\title{
Clinical profile of maternal deaths due to postpartum haemorrhage
}

\author{
Vidyadhar B. Bangal*, Parikshit Jondhale, Satyajit Gavhane, Krupa Mange
}

Department of Obstetrics and Gynecology, Rural Medical College, Loni, Rahata, Ahmednagar, Maharashtra, India

Received: 19 May 2020

Accepted: 29 June 2020

\section{*Correspondence:}

Dr. Vidyadhar B. Bangal,

E-mail: vbb217@rediffmail.com

Copyright: ( ) the author(s), publisher and licensee Medip Academy. This is an open-access article distributed under the terms of the Creative Commons Attribution Non-Commercial License, which permits unrestricted non-commercial use, distribution, and reproduction in any medium, provided the original work is properly cited.

\section{ABSTRACT}

Background: Postpartum haemorrhage is one of the dreadful complications that occur during delivery. It is often unanticipated and occurs suddenly and un-expectedly. It is responsible for 20 percent of maternal deaths in developing countries. These deaths are largely preventable. The objective of the study was to find out the clinical profile, associated co-morbid conditions and contributory factors and treatment modalities used in the management.

Methods: Retrospective observational study of maternal deaths due to postpartum haemorrhage (PPH) was carried out at tertiary care hospital. The data of maternal deaths for seven years from year 2013 to 2019 was reviewed, compiled and analyzed to draw conclusions.

Results: There were 18 maternal deaths (19\%) due to PPH out of total 86 maternal deaths. The average age of the woman who died due to PPH was 24 years. Ninety five percent of the cases of PPH were due to atonic uterus. Seventy percent of the cases had reported in advanced stage of shock with average blood loss of more than two to three litres. Poor general condition due to delay in reaching to tertiary care hospital was predominant feature. Sixty percent women underwent obstetric hysterectomy. Massive blood transfusion was given in fifty percent cases. Severe pregnancy induced hypertension, severe anaemia and severe concealed accidental haemorrhage were common associated factors in sixty percent of maternal deaths.

Conclusions: Postpartum haemorrhage is still a common cause of maternal death. Early detection, prompt aggressive management, adequate blood replacement, use of uterine balloon tamponade and non-pneumatic anti-shock garment, timely transfer to higher centre and timely decision for surgical interventions can prevent maternal deaths.

Keywords: Maternal mortality ratio, Non pneumatic anti-shock garment, Obstetric hysterectomy, Postpartum haemorrhage, Shock index, Uterine balloon tamponade

\section{INTRODUCTION}

Postpartum haemorrhage (PPH) is a life-threatening complication that occurs suddenly and unexpectedly. It is the most commonly reported complication and the leading cause of maternal deaths $(29.6 \%) .{ }^{1} \mathrm{PPH}$ is defined as blood loss $\geq 500 \mathrm{ml}$ within 24 hours after birth, while severe PPH is blood loss $\geq 1000 \mathrm{ml}$ within 24 hour. ${ }^{2}$ The incidence of PPH from India had been reported to be $2 \%-4 \%$ for vaginal deliveries and $6 \%$ for caesarean sections, with uterine atony being the main cause in almost $50 \%$ of the cases. ${ }^{3,4}$ Around 140,000 deaths, equating to 1 every $4 \mathrm{~min}$, happen as a result of this complication globally. ${ }^{5,6}$ Once bleeding starts, death can occur in around 2 hours, which leaves a little time for safe referral and effective care, unless available immediately. A better understanding of the factors associated with PPH maternal mortality is critical for preventing maternal deaths. The purpose of this study was to understand through maternal death case reviews, about various direct and indirect contributors of maternal death due to PPH.

\section{METHODS}

A retrospective observational study was carried out for a period of seven years at tertiary care hospital located in rural area in Maharashtra, India. Approximately 10,000 
deliveries take place per year in this hospital. Majority of complicated and high-risk cases are referred to this hospital from nearby towns and villages. The hospital has blood bank facility 24 hours a day. Initial assessment of every PPH case is done in obstetric triage. As soon as severe shock was recognized, the anti-shock garment was placed around patient. Blood loss was estimated through clinical and laboratory parameters and treatment is instituted immediately as per PPH management protocol. Shock index was calculated. Vital signs were monitored every 15 minutes, hourly urine output and intermittent oxygen saturation were used to monitor patients during the use of the anti-shock garment. Definitive medical or surgical management of cases was done. Cases of severe PPH in shock were managed in obstetric HDU and were shifted to surgical intensive care unit following any major surgical intervention. Massive blood transfusion was given, whenever indicated.

Case record of every maternal death due to postpartum haemorrhage was reviewed. The discussion points of the case during maternal death surveillance and response (MDSR) were noted. The information on variables like age, parity, antenatal registration, type of delivery, place of delivery, cause for PPH, time interval between $\mathrm{PPH}$ and admission to tertiary care hospital, time interval between PPH and death, condition of patient at the time of admission, shock index, type of treatment given to case and subsequent outcome was noted.

\section{Statistical analysis}

The data was collected, compiled, analyzed to draw conclusions of the study.

\section{RESULTS}

There were 60,965 deliveries during seven years study period. During this period there were 86 maternal deaths with maternal mortality ratio of 141 per one lakh live births. There were 18 maternal deaths due to postpartum haemorrhage, thus approximately 19 percent of maternal deaths were due to postpartum haemorrhage. It was observed that 61 percent of the maternal deaths occurred in the age group of 20-25 years and 33 percent maternal deaths were in the age group of 26-30 years. There was no death in a teenage mother. Only one maternal death took place in a woman above 30 years (Table 1 ).

Sixty one percent of maternal deaths took place in multiparous women and thirty nine percent in primi parous women. There was no death in grand multi-parous woman. Ninety four percent of the women who died were un registered to the hospital. Seventy percent of them were registered with some other hospital, either in public or private health facility (Table 1).

The average distance between referring hospital and referral hospital was 30 kilo-meters with fairly good road conditions. The time interval between referral from peripheral hospital and admission to referral hospital was 1-2 hour and 3-4 hours each in twenty seven percent cases. Forty six percent cases reported to referral hospital after four hours of referral (Table 1).

Table 1: General profile of cases of maternal deaths.

\begin{tabular}{|c|c|}
\hline $\begin{array}{l}\text { General profile of cases of } \\
\text { maternal deaths }\end{array}$ & No. $(\%)$ \\
\hline \multicolumn{2}{|l|}{ Age group } \\
\hline Less than 20 years & $0(0.00 \%)$ \\
\hline $20-25$ years & $11(61.10 \%)$ \\
\hline $26-30$ years & $6(33.33 \%)$ \\
\hline Above 30 years & $1(5.55 \%)$ \\
\hline \multicolumn{2}{|l|}{ Parity } \\
\hline Primi & $7(38.90 \%)$ \\
\hline Para 2-para 4 & $11(61.10 \%)$ \\
\hline Para 5 and above & $0(0.00 \%)$ \\
\hline \multicolumn{2}{|l|}{ Registration status } \\
\hline Registered & $1(5.55 \%)$ \\
\hline Unregistered & $17(94.44 \%)$ \\
\hline \multicolumn{2}{|c|}{$\begin{array}{l}\text { Time interval between PPH and admission to } \\
\text { tertiary care hospital }\end{array}$} \\
\hline Up to 1 hour & $0(0.00 \%)$ \\
\hline 1-2 hours & $2(11.10 \%)$ \\
\hline 3-4 hours & $3(16.66 \%)$ \\
\hline More than 4 hours & $5(27.77 \%)$ \\
\hline \multicolumn{2}{|l|}{ Co morbid conditions } \\
\hline Yes & $12(66.66 \%)$ \\
\hline No & $6(33.33 \%)$ \\
\hline \multicolumn{2}{|c|}{ Associated co morbid condition } \\
\hline Anaemia & $2(11.10 \%)$ \\
\hline $\mathrm{PIH}$ & $3(16.66 \%)$ \\
\hline Liver disorder & $1(5.55 \%)$ \\
\hline APH & $4(22.22 \%)$ \\
\hline Thrombocytopenia & $1(5.55 \%)$ \\
\hline \multicolumn{2}{|c|}{ Interval between PPH and death } \\
\hline Less than six hours & $2(11.10 \%)$ \\
\hline 6-24 hours & $10(55.55 \%)$ \\
\hline 24-48 hours & $5(27.77 \%)$ \\
\hline 48-72 hours & $1(5.55 \%)$ \\
\hline More than 72 hours & $0(0.00 \%)$ \\
\hline
\end{tabular}

Eighty eight percent cases had atonic type of PPH, whereas six percent cases each, had either traumatic or mixed type of PPH. Sixty seven percent cases had associated co morbid conditions. Common among them were pregnancy induced hypertension $(25 \%)$, accidental haemorrhage $(25 \%)$, liver disorder $(8 \%)$, anaemia $(75 \%)$ or thrombocytopenia (8\%) (Table 1).

Eleven percent cases died in less than six hours of PPH. Sixty seven percent cases died in between 6 hours and first 24 hours of $\mathrm{PPH}$, twenty eight percent died in between 24-48 hours and six percent died within 48-72 hours of development of PPH (Table 1). Forty five percent of women had delivered private nursing home or 
maternity hospital, thirty nine percent had delivered at tertiary care hospital and remaining sixteen percent had delivered in public health facility (Table 2).

The mode of delivery in sixty six percent cases was by vaginal route and remaining forty percent were delivered by caesarean section (Table 2 ).

Table 2: Clinical profile of cases of maternal deaths.

\begin{tabular}{|ll|}
\hline $\begin{array}{l}\text { Clinical profile of cases of maternal } \\
\text { deaths }\end{array}$ & No. $(\%)$ \\
\hline Place of delivery & $3(16.66 \%)$ \\
\hline Public health facility & $8(44.44 \%)$ \\
\hline Private nursing home & $7(38.90 \%)$ \\
\hline Medical college hospital & \\
\hline Mode of delivery & $12(66.66 \%)$ \\
\hline Spontaneous vaginal & $0(0.00 \%)$ \\
\hline Instrumental vaginal & $6(33.33 \%)$ \\
\hline Caesarean section & \\
\hline Type of PPH & $16(88.90 \%)$ \\
\hline Atonic & $1(5.55 \%)$ \\
\hline Traumatic & $1(5.55 \%)$ \\
\hline Mixed & \\
\hline Haemoglobin level on admission & $6(33.33 \%)$ \\
\hline Less than 4 grams & $8(44.44 \%)$ \\
\hline 4-7 grams & $3(16.66 \%)$ \\
\hline 7-10 grams & $1(5.55 \%)$ \\
\hline More than 10 grams & \\
\hline Shock index & $0(0.00 \%)$ \\
\hline Up to 0.7 & $0(0.00 \%)$ \\
\hline 0.8-up to 1 & $8(44.44 \%)$ \\
\hline 1-2 & $3(16.66 \%)$ \\
\hline More than 2 & $7(38.90 \%)$ \\
\hline Un-recordable blood pressure and pulse & \\
\hline Management & $6(33.33 \%)$ \\
\hline Medical management & $0(0.00 \%)$ \\
\hline Surgical management & $11(61.11 \%)$ \\
\hline Medical +surgical & $16(88.88 \%)$ \\
\hline ICU management & $10(55.55 \%)$ \\
\hline Massive blood transfusions & $11(61.11 \%)$ \\
\hline Surgical interventions & $3(16.66 \%)$ \\
\hline Obstetric hysterectomy & $5(27.77 \%)$ \\
\hline B-Lynch compression suture & \\
\hline Stepwise devascularisation & \\
\hline & \\
\hline
\end{tabular}

Shock index was calculated in obstetric triage on arrival. Forty four percent cases had second degree (estimated blood loss of 1-2 litres) shock, seventeen percent had third degree (estimated blood loss of 2-3 litres) and thirty nine percent cases had forth degree (estimated blood loss of more than 3 litres) shock (Table 2).

Blood haemoglobin was estimated at the time of admission. Seventy eight percent cases had severe anaemia (blood haemoglobin level of less than seven percent). Thirty four percent cases had haemoglobin level of less than 4 grams percent (Table 2).

Sixty one percent cases required combined medical and surgical management. Thirty nine percent cases were managed by only medical method. Surgical interventions in the form of obstetric hysterectomy was performed in sixty one percent cases, B-Lynch compression suture was applied in 17 percent cases and step wise devascularisation was done in twenty eight percent cases. Eighty eight percent cases were transferred to intensive care unit and fifty six percent cases required massive blood transfusion in the form of packed cell volume, fresh frozen plasma or platelets (Table 2).

\section{DISCUSSION}

Postpartum haemorrhage (PPH) is the leading cause of maternal mortality in India. It is unfortunate that young women are dying during the physiological process of delivery. This complication occurs irrespective of place of delivery and mode of delivery. It is very important that all deliveries are conducted at a place, where there is complete preparedness for management of this complication. If the woman developed $\mathrm{PPH}$ in a secondary or tertiary level hospital, the immediate medical and surgical interventions are possible to save her life. It is not so, when woman delivers at home or in a small ill-equipped hospital. Extra care must be taken, when there is some high-risk factor is identified during course of pregnancy, which can result in to PPH. At times there is no detection of high-risk factors or there is ignorance about it, leading to catastrophe.

It was observed in the present study that average age of a woman who died due to PPH was only 24 years. This is because of early age of marriage in Indian culture and lack of contraceptive use. It was observed that there were more deaths among multipara than primipara. There were no deaths among grand multipara in the present study group.

Timely diagnosis of $\mathrm{PPH}$ and decision to transfer to hospital or tertiary care centre is very crucial. Time lapse between occurrence of PPH and reaching to tertiary care facilities determines the outcome. Unfortunately, there is very narrow margin of safety as regards to time. Treatment received in first two hours, following $\mathrm{PPH}$ determines the survival. Crucial time is lost in transfer of patient to higher centres. At times, patients are transferred as per transfer protocols of the health care centres, which may further result into delay in reaching to tertiary care centres, as small health facilities, including primary health centres and rural hospitals are not equipped and do not have specialist doctors and blood transfusion facilities. In the present study, delay was observed in cases referred from private nursing homes. In lowresource settings, delays in identifying hemorrhage, delays in transport to facilities from a home birth or from primary care centers, and delays in receiving definitive 
therapies upon arrival at tertiary facilities contribute to high rates of maternal mortality and morbidity secondary to hypovolemic shock. ${ }^{7}$

In the present study, prior communication to referral hospital was not done in $50 \%$ cases. If there is prior communication from referring centre to referral centre, the referral hospital can organize the emergency team and the set-up, by the time case is received in the triage. Referral hospital can also pass on some instructions or suggestions to referring centre regarding treatment during transfer. Referring hospital must send a referral chit with all important salient features of the case that includes mention about the vital parameters and the treatment given to the case before transfer. Unfortunately, many referring centres either do not give details of the condition and treatment or give false information with the fear of medico legal litigations.

In the present study, it was observed that the average distance from referring hospital to referral hospital was approximately 25-30 kilo-meters with actual travel time of 30-40 minutes. Not a single case reached to the referral hospital within one hour of PPH. The time between occurrence of PPH and admission to referral hospital was up to two hours in twenty seven percent cases, was up to three hours in twenty seven percent cases and was more than three hours in forty six percent cases. These findings suggest significant delay in transfer of these cases. Delay in diagnosis of PPH and decision making for transfer and arranging transfer are two main reasons for delay in admission to referral hospital. In eighty percent cases, there was no proper referral chit with the case. The treating physician had to call up the referring centre to get additional treatment details.

There are many studies that have proven the importance of stabilization of patient through first aid and timely transfer. A pregnant woman suffering from severe haemorrhage can die within two hours, unless she receives immediate and prompt medical care; therefore, when delay in managing haemorrhage occurs, first aid is needed to resuscitate and stabilize women with hypovolemic shock until definitive treatment is obtained..$^{8-10}$

In the present study, all cases of maternal deaths due to postpartum haemorrhage had high shock index. Forty five percent cases had estimated blood loss of around 2 litres, seventeen percent cases had estimated blood loss of around three litres and thirty nine percent women had estimated blood loss of more than three litres. These cases of severe blood loss had come with un-recordable blood pressure and pulse at the time of admission. Four cases were admitted in gasping condition and were intubated in triage area and immediately shifted to operation theatre or intensive care unit for further management. It was observed that shock index at the time of admission in cases postpartum haemorrhage predicts the maternal outcome as regards to survival.
In the present study, sixty six percent women had vaginal delivery and remaining thirty four percent had undergone caesarean section. Seven out of eighteen maternal death cases had delivered at Pravara Rural hospital. There were three cases of severe concealed accidental haemorrhage referred from outside, which either had vaginal delivery or caesarean section. There was severe couvelaire uterus in all the cases resulting in severe uterine atony. There were two cases of placenta previa increta. The bleeding could not be controlled by medical and surgical methods. These women had severe degree of shock, in spite of replacement of blood and blood products. There were two cases of complete inversion of uterus with severe hemorrhagic shock, who had delivered at government hospital and referred in sever degree of hemorrhagic shock. Medical and surgical interventions did not result in improvement in shock.

Surgical intervention in the form of either B Lynch suture or stepwise devascularization including internal iliac ligation was performed in 8 cases and obstetric hysterectomy was required in 11 cases. In spite of availability of all modalities of treatment for PPH under one roof, expert opinion, surgical expertise, ICU with intensivist back-up, senior anesthetists and availability of adequate blood and component therapy, these deaths could not be averted. The main reason being delay in diagnosis and decision to refer and delay in transport. On availability of adequate blood and blood components facility at peripheral hospitals have contributed in rapid deterioration of condition of the patient. In order to maintain the blood pressure, multiple bottles of intravenous fluid and plasma expanders are infused by the private practitioners, which later on resulted in dilutional coagulopathy. Out of 11 cases, who were referral in from smaller hospitals, only two cases came with two intravenous lines. Five cases had working single intravenous line and remaining four had no intravenous line.

There is definite role of uterine balloon tamponade (UBT) in management of atonic PPH. The device is easy to use, cheap and can be inserted by health worker like ANM or medical officer at primary health centres. There is enough evidence in support of usefulness of UBT in control or reduction of atonic PPH. ${ }^{11-17}$ The UBT can either control or stop the blood loss or at least reduce the blood loss in severe cases of atonic PPH, while patient is being transferred to higher centre. Training of PHC staff in diagnosis of atonic PPH and differentiating between atonic and traumatic PPH is essential before introduction of UBT.

Results from the use of the Non-pneumatic Anti- Shock Garment (NASG) to stabilize women with obstetric haemorrhage have been published in a case series, a pilot study, and two small comparative studies. ${ }^{18-22}$ The nonpneumatic anti-shock garment (NASG) is a first-aid device that can save lives of women experiencing obstetric haemorrhage from any aetiology. ${ }^{23}$ The NASG 
is a simple neoprene and Velcro device that looks like the bottom half of a wetsuit cut into segments. The use of the NASG reportedly addresses the immediate lifethreatening complication by reversing hypovolemic shock among mothers having shock due to PPH and returns blood to the heart, lungs, and brain by applying pressure to the lower body and abdomen. ${ }^{24}$ The use of an NASG can stabilize a patient while awaiting transport, during transport, or during delays in receiving care at referral facilities. ${ }^{25-27}$ A cluster randomized clinical trial (CRCT) was conducted in Zimbabwe and Zambia to determine if early application of the NASG at the primary health facility level improved outcomes compared to later application at the referral facilities. ${ }^{28}$

Preparedness of tertiary care centre to deal with obstetric emergencies is very essential. Avoidance of any delay helps in reducing the blood loss. Intelligent anticipation regarding $\mathrm{PPH}$, while delivering high risk woman helps in immediate interventions. Prompt communication at every level saves time and improves outcome. Communication from peripheral hospitals to a referral hospital before shifting the patient is helpful. That confirms the availability of specialist at the referral hospital and tertiary care centre gets time for it preparedness to deal with the emergency. Operation theatre and surgical team can be spared or prepared during transit time of the patient. Encouraging institutional delivery has all the advantages as stated above. It reduces the need for transfer and saves time, limits the blood loss and keeps the patient condition stable till definite management is planned. High-risk pregnancies are prone for development of PPH. Detection of high-risk factors by peripheral health workers and timely transfer to higher centre can avoid the complication like PPH. Severe anaemia, severe hypertension, liver disorders and women with previous history of third stage complications must be refereed to higher centres for further evaluation. Delivery plan must be ensured for these women. The patient and relatives must be told about the risk of haemorrhage and risk to life of the woman. Every primary health centre must keep its labour room ready for management of PPH. PPH tray must have all essential drugs especially the oxytocic drugs. A checklist of contents of PPH tray must be available in labour room. ANM and medical officers at PHC must monitor round the clock availability of essential drugs in PPH tray. Regular refresher training of PHC staff on common obstetric emergencies will help in improving their knowledge and skills required in saving lives.

Many maternal deaths can be avoided, if these women get blood and surgical interventions at the referral hospital, especially at maternity homes run by gynecologist or Ayurveda practitioners. Presently, the cases are referred to higher centres in shock due to the fear of litigations or fear of damage to the hospital and physical harm to doctor or owner of the hospital by relatives or the mob, if woman dies in their set up. Instead, if a team of specialist doctors available in the vicinity or the town come together and act quickly in order to save the woman, many deaths can be avoided.

\section{CONCLUSION}

Atonic postpartum haemorrhage is common among high risk pregnancies. Its incidence can be lowered by universal adoption of AMTSL. Institutional deliveries will help prevent and mange this complication in a effective manner. Facility preparedness in all respect will prevent deaths due to atonic PPH. Wise and prompt decisions regarding use of different modalities or combination of modalities will save lives. Technical expertise, confidence and surgical skills are essential to manage complicated cases. Anaesthesia, ICU back up and availability of blood and component facilities improve clinical outcome. Avoidance of delays in diagnosis and transfer, high risk pregnancy identification and timely referral, capacity building of peripheral health workers in use of medication and uterine balloon therapy and non-pneumatic anti-shock garment will go a long way in reducing the maternal mortality related to atonic postpartum haemorrhage.

Funding: No funding sources Conflict of interest: None declared

Ethical approval: The study was approved by the Institutional Ethics Committee

\section{REFERENCES}

1. Khan KS, Wojdyla D, Say L, Gülmezoglu AM, Van Look PF. WHO analysis of causes of maternal death: a systematic review. Lancet. 2006;367:1066-74.

2. World Health Organization Library. WHO Recommendations for the prevention and treatment of postpartum haemorrhage. Geneva, Switzerland: World Health Organization Library; 2012.

3. Amy JJ. Severe postpartum haemorrhage: a rational approach. Natl Med J India. 1998;11:86-8.

4. Rao KA. Presidential address. The $44^{\text {th }}$ all India obstetric and gynecological congress. J Obstet Gynecol India. 2001;51:25-8.

5. Abou Zahr C. Global burden of maternal death and disability. Br Med Bull. 2003;67:1-11.

6. American College of Obstetricians and Gynecologists. ACOG practice bulletin: Clinical management guidelines for obstetriciangynecologists number 76, October 2006: postpartum hemorrhage. Obstet Gynecol. 2006;108:1039-47.

7. McCarthy J, Maine D. A framework for analyzing the determinants of maternal mortality. Stud Fam Plann. 1992;23:23-33.

8. Balachandram V. Maternal Mortaltiy in Kaduna, Nigeria Med J. 1995;5:366-70.

9. Bias JM, Eskes M, Pel M, Bonsel GJ, Bleker OP. Postpartum hamorrhage in Wulparous women: incidence and risk factors in low and high-risk 
women. Eur J Obstet Gynecol Reprod Bwl. 2004;115(2):166-72.

10. Magann EF, Evans S, Flutechnison M, Collins R, Lanneau G, Mirrison JL. Postpartum heamorhage after cesarean delivery: an analysis of risk factors. S Med J. 2005;98:618-5.

11. Tindell K, Garfinkel R, Abu-Haydar E, Ahn R, Burke TF, Conn K, et al. Uterine balloon tamponade for the treatment of postpartum haemorrhage in resource-poor settings: a systematic review. BJOG. 2013;120:5-14.

12. Burke TF, Ahn R, Nelson BD, Hines R, Kamara J, Oguttu M, et al. A postpartum haemorrhage package with condom uterine balloon tamponade: a prospective multi-centre case series in Kenya, Sierra Leone, Senegal, and Nepal. BJOG. 2016;123:153240 .

13. Pendleton AA, Natarajan A, Ahn R, Nelson BD, Eckardt MJ, Burke TF. Emergency hysterectomy for uncontrolled postpartum hemorrhage may be averted through uterine balloon tamponade in Kenya and Senegal. Int J Gynecol Obstet. 2016;133:124.

14. Pendleton AA, Natarajan A, Ahn R, Nelson BD, Eckardt MJ, Burke TF. A qualitative assessment of the impact of a uterine balloon tamponade package on decisions regarding the role of emergency hysterectomy in women with uncontrolled postpartum hemorrhage in Kenya and Senegal. BMJ Open. 2016;6:e010083.

15. Herrick T, Mvundura M, Burke TF, Abu-Haydar E. A low-cost uterine balloon tamponade for management of postpartum hemorrhage: modeling the potential impact on maternal mortality and morbidity in sub-Saharan Africa. BMC Preg Childbirth. 2017;17(1):374.

16. Mvundura M, Abu-Haydar E, Okoth E, Okoth E, Herrick T, Mukabi J, et al. Cost effectiveness of the uterine balloon tamponade to control severe postpartum hemorrhage in Kenya. Int J Gynaecol Obstet. 2017;137:185-91.

17. Burke T, Danso-Bamfo S, Cappetta A, Masaki C, Guha M, Oguttu M, et al. An ultra-low cost uterine balloon tamponade package saves lives among women with advanced shock from uncontrolled postpartum hemorrhage in low resource settings. Ann Global Health. 2017;1(83):97-8.

18. Brees C, Hensleigh PA, Miller S, Pelligra R. A noninflatable anti-shock garment for obstetric hemorrhage. Int J Gynaecol Obstet. 2004;87:119-24.

19. Hensleigh PA. Anti-shock garment provides resuscitation and haemostasis for obstetric haemorrhage. BJOG. 2002;109:1377-84.

20. Miller S, Fathalla MM, Youssif MM, Turan J, Camlin C, Al-Hussaini TK, et al. A comparative study of the non-pneumatic anti-shock garment for the treatment of obstetric hemorrhage in Egypt. Int $\mathrm{J}$ Gynaecol Obstet. 2010;109:20-4.

21. Miller S, Hamza S, Bray E, Gipson R, Nada K, Fathalla MF, et al. First aid for obstetrical haemorrhage: the pilot study of the non-pneumatic anti-shock garment (NASG) in Egypt. BJOG. 2006;113:424-9.

22. Miller S, Ojengbede O, Turan JM, Morhason-Bello IO, Martin HB, Nsima D. A comparative study of the non-pneumatic anti-shock garment for the treatment of obstetric hemorrhage in Nigeria. Int J Gynaecol Obstet. 2009; 107:121-5.

23. Turan J, Ojengbede O, Fathalla M, Mourad-Youssif M, Morhason-Bello IO, Nsima D, et al. Positive effects of the non-pneumatic anti-shock garment on delays in accessing care for postpartum and postabortion hemorrhage in Egypt and Nigeria. J Womens Health). 2011;20:91-8.

24. Non-pneumatic Anti-shock Garment-Compendium of New and Emerging Technologies that Address Global Health Concerns. Geneva: World Health Organization; 2011. Available at: http://www.who.int/medical_devices/innovation/new _emerging_tech_30.pdf. Accessed on $12^{\text {th }}$ April 2020.

25. Pileggi-Castro C, Nogueira-Pileggi V, Tunçalp Ö, Oladapo OT, Vogel JP, Souza JP. Non-pneumatic anti-shock garment for improving maternal survival following severe postpartum haemorrhage: a systematic review. Reprod Health. 2015;12:28.

26. Maknikar S, Nanda R, Miller S. NASG reduces mortality in Indian women with PPH. Int J Gynecol Obstet. 2012;119:S413.

27. Magwali T, Butrick E, Mambo V, Ayadi A, Lippman $\mathrm{S}$, Bergel E. Non-pneumatic anti-shock garment (NASG) for obstetric hemorrhage: Haraze, zimbabwe. Int J Gynecol Obstet. 2010;119:S410.

28. Miller S, Bergel EF, El Ayadi AM, Gibbons L, Butrick EA, Magwali T, et al. Non-pneumatic antishock garment (NASG), a first-aid device to decrease maternal mortality from obstetric hemorrhage: a cluster randomized trial. Abdel-Aleem $\mathrm{H}$, editor. PLoS One. 2013;8(10):e76477.

Cite this article as: Bangal VB, Jondhale $\mathrm{P}$, Gavhane S, Mange K. Clinical profile of maternal deaths due to postpartum haemorrhage. Int J Reprod Contracept Obstet Gynecol 2020;9:3243-8. 